\title{
Effective Strategies of Construction Design and Management in Construction Site
}

\author{
Jianhui Wang* \\ Tianmeng Construction Co., Ltd. E-mail: jhwang@163.com
}

\begin{abstract}
At present, all walks of life are carrying out deepening reforms, and the construction industry is exploring scientific and more feasible technical management measures to ensure the engineering quality of enterprises. Based on this, this paper briefly expounds the problems existing in the process of construction project management and construction design control, and puts forward a series of effective measures for Europeanization of construction design, aiming at improving the overall construction level of the construction industry and promoting the rapid development of the construction industry.
\end{abstract}

Keywords: Construction Engineering; Engineering Management; Construction Design

\section{Introduction}

At present, great achievements have been made in the field of construction, but many quality problems have also been exposed. To achieve sustainable development, construction units must formulate targeted measures to solve the management and quality problems existing in construction projects, so as to ensure the quality of construction projects.

The problems existing in the process of construction engineering management and construction design control

Subcontracting management mechanism is a common management mechanism in construction engineering. Subcontracting management means contracting the project to an external construction team, and then the external construction team dispatches construction technicians to carry out various construction operations. Although the establishment of this management mechanism saves economic costs to a certain extent, its drawbacks are more obvious. This kind of management mechanism splits each process, and the mode of block construction is easy to miss steps. It is also difficult for the construction party to manage the construction team as a whole. Up to now, the original construction technology still exists, which is essentially the same as the operation steps of the original construction. Construction workers should not abandon the previous construction technology, but still master the original basic construction technology. Only in this way can practice make perfect in construction. The main reason why the construction design is difficult to be improved is that the construction personnel lack professional skills. Most of the construction personnel are farmers, who go to work directly without systematic theoretical study. When many technical problems cannot be overcome in the construction process, they are often ignored directly, which makes it difficult to maintain the continuity of the construction process and guarantee the construction quality of buildings. 


\section{Improve the construction site construction technology and management measures}

\subsection{To establish the awareness of construction project management and construction design control}

If a construction enterprise wants to fundamentally improve its own construction level and maximize its internal management work, it must explore the essence of construction engineering management and construction design. Only by having a precise understanding of its essence, the construction party can truly implement the contents stipulated by construction engineering management and construction design control, and finally establish a correct construction concept. This requires the construction enterprises to formulate corresponding measures from two points: first, the importance of construction project management and construction design control should be vigorously publicized to the construction workers, so that the construction workers can understand that the quality level of the buildings built under this management mode is higher, and their work efficiency can be greatly improved. Only when the construction workers have personally realized the positive significance of these two aspects of work, can they be more willing to accept management. Second, the management personnel of construction enterprises should do their own work well, strengthen the intensity of construction project management and construction design control, and constantly improve the management content to ensure that the implementation of the management content is more feasible. The best way is to create a team related to the management work, and let the team members go deep into the grassroots to guide the unreasonable behaviors of construction workers, so as to ensure that the management work is implemented in all aspects of construction projects.

\subsection{To strengthen the professional training of construction personnel}

Nowadays, the social competition is fierce, the professional level of personnel is improved, the social competitive advantage is strengthened, and the construction design can be ensured. Therefore, the unit should first solve the professional ability of construction personnel, and at the same time, through making reasonable plans, let employees realize their own shortcomings and make targeted improvements. For example, the construction personnel should be trained in engineering professional knowledge and safety education. For managers, they should strengthen their management skills, safety education and professional quality through training. At the same time, managers should arrange jobs according to the characteristics of different employees, improve the team consciousness and cooperation spirit of all employees, and promote the implementation of management. In addition, regarding the construction progress of the construction project, it is necessary to establish the project manager responsibility system, establish a strict assessment system, and reward and punish according to the performance of different employees. Both managers and construction personnel should follow the basic management concepts, be responsible for their own tasks, and ensure the quality, safety and timely completion of the project. In practical work, managers need to establish a perfect quality management framework, and clarify the duties, work contents, rights and responsibilities of personnel at different levels.

In this paper, the quality management level of construction engineering is divided into three levels, from the project manager or engineer at the decision-making management level to the full-time quality manager or engineer at the executive level, and finally, the on-site quality inspector makes the construction engineering inspection work. The three levels of quality management involve the planning stage, resource preparation stage, construction stage and final inspection stage of construction engineering, which is a full-process comprehensive management form. In the above-mentioned management level, the managers of construction projects need to strengthen the quality supervision in engineering design and planning stage, and set up independent quality inspection departments to restrain the behavior of middle and high-level decision makers, so as to improve the efficiency and effect of quality management. Clear rights and responsibilities need to be carried out before the supervision work is carried out. The division of rights and responsibilities 
can be carried out jointly with the government and relevant departments, mainly by strictly testing the quality of main building materials and engineering entities, providing supervision basis for quality supervision departments, and supervising the implementation of rights and responsibilities of multi-responsible subjects. In addition, the regulatory authorities need to take "the quality of engineering entities" as the main supervision object, and change the traditional supervision mode of "the quality behavior of the responsible subjects of all parties involved in the construction" to ensure that the supervision responsibilities are effectively implemented.

\subsection{To strengthen the management of construction design}

By controlling the construction design, a project evaluation team can be established to evaluate the building quality problems in time, so as to carry out the quality management work efficiently. The construction personnel should also ensure the standardized construction, do a good job in the field survey, work out a reasonable construction scheme according to the field conditions, and carry out the field operation on the basis of familiarizing and understanding the drawings. It should be noted that the construction site of building engineering involves many factors such as technology, materials and personnel. In order to ensure the realization of the engineering quantity target, it is necessary to strengthen the intensity of material inspection, technical guidance and personnel training, and ensure that the overall level of site construction is improved on the basis of advanced material quality and technology. When the project is about to be completed, the project quality acceptance should also be strengthened, and once safety risks occur, rework should be done immediately. In the preparation stage of related construction, special attention should be paid to the early maintenance work and the transportation of materials, and the loss of materials during transportation should be reduced. It is also necessary to store materials reasonably by classification. Because different materials have different characteristics, all materials cannot be simply stacked together, so as not to affect the quality of materials. Finally, the construction equipment will be checked to ensure that it can work normally during construction. In the key links during the expansion joint operation, the mix proportion of concrete should be well controlled, so as to enhance the structural stability and waterproof degree of concrete. In addition, the gap of concrete formwork needs to have high tightness, and the strength also needs to meet the prescribed standards. When pouring concrete, it needs to be pounded on both sides at the same time. When the pouching is finished, plastic film and geotextile are used to cover it, and at the same time, wine is used to keep moisture. After the strength of concrete reaches the specified standard, it can be used. During the construction of road expansion joints, the relevant staff must ensure the stability and reliability of the welding parts, and must also accurately carry out the prevention and control activities of each assembly of expansion joints.

\subsection{Establish a scientific supervision and management mechanism}

To improve the management and quality control level of construction projects, a scientific and reasonable supervision and management mechanism should be established, so that the staff can strictly abide by the construction specifications and ensure the implementation of project quality management responsibilities. At the same time, construction enterprises need to strengthen supervision and constantly improve the supervision work. They should supervise and accept according to laws, regulations and contracts to ensure the management and construction design of construction projects. By analyzing the control situation of construction engineering management and construction design in China, it is found that there are still many problems in the management system. Therefore, the construction management system should be optimized to improve the management concept, comprehensively analyze the construction situation in this process, and arrange the jobs and tasks of construction personnel in combination with comprehensive factors. The construction unit should also be aware of the importance of construction management and constantly update its own management concept. It is also important to find out the problems in the management process in time, and establish a management system suitable for its own development. With the emergence of new machinery and construction 
technology, advanced mechanical construction equipment has been popularized in the engineering field. However, in the popularization process, efforts should be made to prevent quality problems caused by operation errors, save investment costs and ensure construction progress.

\subsection{The management concept and construction technology innovation}

In the innovation of construction management in construction engineering enterprises, the first step is to innovate ideas. Only by changing ideas can the management methods and achieve the effect of green construction be better changed. For example, construction design and cost control should be carried out in the whole process of project implementation, and advanced information management measures should be continuously introduced to make the project management reach automation standards. The necessary innovation of construction technology can promote the improvement of engineering quality, reduce construction cost and protect the surrounding natural environment. For example, the construction technology of external wall self-insulation system currently includes several materials such as autoclaved fly ash brick, autoclaved aerated concrete block and ceramsite block, which are made of different raw materials and have different functions. Choosing energy-saving point insulation measures in wall materials and applying energy-saving wall materials in construction can ensure that the temperature inside the building reaches the appropriate standard and improve people's quality of life, at the same time, it has a very strong energy-saving effect, avoiding adverse effects on the natural environment and solving the environmental pollution problem.

\subsection{Improve the overall quality of managers}

The work requirements of employees and the recruitment of new personnel should be strictly in accordance with the relevant rules and standards, so that each person can clearly define his own responsibilities and consciously standardize them, so as to ensure the quality of construction and the safety of relevant construction personnel, and further ensure the overall quality of construction. The construction link is very cumbersome, so in order to improve the technical application level, technical disclosure must be carried out in the early stage of construction. Construction enterprises should provide on-the-job training for construction project managers, so that they can improve their comprehensive quality in the process of continuous learning. Construction enterprises should regularly hire professional management instructors to teach internal management personnel. The main teaching content is some measures to improve the management level of internal personnel, so as to improve the work quality of management personnel. In addition, managers should be assessed regularly and corresponding rewards and punishments should be formulated. Under this pressure, managers are willing to participate in management work independently. Relevant managers should be organized to set up departments related to management work, corresponding management systems should be formulated by virtue of past work experience and the current situation of construction teams, and sound management mechanisms should be arranged in written form, so that construction personnel can serve as reference to correct their working attitude. At the same time, managers should consider all aspects when formulating relevant management mechanisms, from safety and quality control content, project quality management system to employees' own reward and punishment system, so as to ensure the steady operation of all construction work.

\section{Conclusion}

On the whole, there are still many problems in construction management and construction control at present. Therefore, it is necessary to improve the control mechanism of construction management and construction design, strengthen the supervision of the whole process of construction, improve the working level of relevant personnel, and effectively guarantee the quality of the project.

\section{References}

1. Zheng X. Aanalysis of main factors affecting construction project management (in Chinese). China Housing Facilities 2019; (12): 127-128.

2. Liu Z. Analysis of the status quo of construction project management and control measures (in Chinese). Jiangxi Building Materials 2019; (12): $207+209$. 
3. Wang H. Application and development analysis of innovative mode in construction engineering management (in Chinese). Jiangxi Building Materials 2019; (12): 216+218. 